\title{
Epidemiological profile of early childhood caries in a sub-urban population in Nigeria
}

\author{
Morenike Oluwatoyin Folayan ${ }^{1 *}$, Ayodeji Babatunde Oginni ${ }^{2}$, Maha El Tantawi ${ }^{3}$, Tracy L. Finlayson ${ }^{4}$ and
} Abiola Adeniyi $i^{2,5}$

\begin{abstract}
Background: The aim of the study was to determine the prevalence and severity of early childhood caries (ECC) in children 6-71-months; identify the teeth most at risk for ECC; and identify risk indicators associated with significant caries index (SiC) score in different age groups.

Methods: This was a cross-sectional study that collected data (using a household survey) on the ECC risk indicators (frequency of tooth brushing, consumption of refined carbohydrate in-between-meals, daily use of fluoridated toothpaste, and dental service utilization in the 12 months) in Ile-Ife, Nigeria. We computed the prevalence of ECC using the International Caries Detection and Assessment System (ICDASI $\left(d^{1-6}\right)$ ) index; caries severity using the ICDAS-2 $\left(\mathrm{d}^{1-2}\right)$ and ICDAS-3 $\left(\mathrm{d}^{3-6}\right)$ for non-cavitated and cavitated lesions respectively, decayed missing, filled teeth (dmft), and surfaces (dmfs) and SiC indices; and caries complications using the pulp (p), ulceration (u), fistula (f) and abscesses (a) (pufa) index, for children 6-11-months-old, 12-23-months-old, 23-35-months-old, 35-47-months-old; 48-59-months-old and 60-71-months-old. The differences in the mean dmft, dmfs, pufa scores, and ICDAS 1, 2, and 3 scores, and proportion of children with each ECC risk indicator were computed. Logistic regression analysis was conducted to identify risk indicators for the ECC SiC index score for each age group.
\end{abstract}

Results: The prevalence of ECC was 4.7\%: $2.9 \%$ had non-cavitated lesions and 2.8\% had cavitated lesions. The mean (SD) dmft, dmfs and pufa scores were 0.13 (0.92), 0.24 (1.91) and 0.04 (0.46) respectively. The dmft and dmfs scores were highest among the 24-35-months-olds while the SiC score was highest among the 12-23-months-olds. There were no significant differences in $\mathrm{dmft}, \mathrm{dmfs}$, and pufa scores between the different age groups. Toothbrushing more than once a day was the only factor associated with the SiC score: it decreases the odds for the SiC score in children 48-59-months-old. The teeth worst affected by ECC were \#85 and \#61.

Conclusion: The prevalence, severity and risk indicator for ECC seems to differ for each age group. The granular details on the risk profile of children with ECC in this population with a low ECC prevalence and burden can allow for the planning of age-targeted interventions.

Keywords: Early childhood caries, Dmft, Dmfs, Pufa, ICDAS, Nigeria

\footnotetext{
*Correspondence: toyinukpong@yahoo.co.uk

${ }^{1}$ Department of Child Dental Health, Obafemi Awolowo University, Ile-Ife,

Nigeria

Full list of author information is available at the end of the article
}

(c) The Author(s) 2021. Open Access This article is licensed under a Creative Commons Attribution 4.0 International License, which permits use, sharing, adaptation, distribution and reproduction in any medium or format, as long as you give appropriate credit to the original author(s) and the source, provide a link to the Creative Commons licence, and indicate if changes were made. The images or other third party material in this article are included in the article's Creative Commons licence, unless indicated otherwise in a credit line to the material. If material is not included in the article's Creative Commons licence and your intended use is not permitted by statutory regulation or exceeds the permitted use, you will need to obtain permission directly from the copyright holder. To view a copy of this licence, visit http://creativecommons.org/licenses/by/4.0/. The Creative Commons Public Domain Dedication waiver (http://creativeco mmons.org/publicdomain/zero/1.0/) applies to the data made available in this article, unless otherwise stated in a credit line to the data. 


\section{Background}

Early childhood caries (ECC) is a disease of public health importance. Caries in primary teeth are the tenth most prevalent disease in children [1]. When left untreated, it has a significant negative impact on the growth and development of the affected child $[2,3]$ and reduces the quality of life of both the child and the caregiver [4]. Caries epidemiological studies help monitor the prevalence of disease and identify associated risk indicators among different age and geographical groups, thus providing new treatment perspectives [5]. The caries profile of a population of young children can be summarized and compared using different indices thereby harnessing the advantages of the indices to derive a comprehensive and relevant epidemiological profile. Several indices are available for assessing dental caries at the population level, each offering various benefits and associated challenges.

An index commonly used to characterize dental caries experience at the tooth level is the decayed (d), missing due to caries $(\mathrm{m})$, and filled $(\mathrm{f})$ teeth $(\mathrm{dmft})$ index. Another similar index is the decayed (d), missing due to caries $(\mathrm{m})$ and filled $(\mathrm{f})$ surfaces $(\mathrm{dmfs})$ index for primary teeth [6]. These indices yield information about the prevalence and severity of caries in an individual, and they are frequently used as a clinical measure for oral health assessment in national surveys [7]. The scores for $\mathrm{dmft}$ range from 0 to 20; and the $\mathrm{dmfs}$ index scores range from 0 to 88. A score of zero indicates no caries, while scores greater than zero indicate the presence of caries, with increasing scores indicating greater severity. The indices had been used for macro-level assessment of the impact of governance on the oral health of children [8]. These indices have remained in use for over 80 years, despite known limitations including an equal weight given to decayed teeth and well-restored teeth; each tooth or tooth surface can be counted only once. Also, it does not provide a valid indication of treatment need and does not account for the number of teeth or surfaces at risk [9-11].

The International Caries Detection and Assessment System (ICDAS) is another established index that enables the detection of non-cavitated and cavitated enamel and dentine caries [12]. Its advantage over the $\mathrm{dmfs} / \mathrm{dmft}$ scoring is its ability to facilitate the detection of non-cavitated lesions, especially enamel caries [13]. ICDAS helps develop a treatment plan [14] thereby overcoming one of the limitations of the $\mathrm{dmft} / \mathrm{dmfs}$ score [15]. ICDAS also has good reproducibility and validity to detect caries lesions and estimate their severity though it seems to overestimate caries activity of cavitated lesions [16]. It also has the disadvantage of long application time when compared with the $\mathrm{dmft} / \mathrm{dmfs}$ indices [17].
The pufa index assesses complications associated with caries which may be more serious than the carious lesions themselves. The presence of teeth with open pulp (p), ulceration (u), fistula (f), and abscesses (a) indicate the severity of the complications associated with a carious tooth [18]. The index is simple to use [19] and has been validated for use in Nigeria [20]. For a country like Nigeria where the prevalence of untreated caries is high [21], the pufa index can provide useful information for policy formation and oral health care planning.

The significant caries index $(\mathrm{SiC})$ is computed based on the mean dmft of one-third of the sample with the highest caries experience scores [22, 23]. It is useful for identifying variations in decay proportions alongside the $\mathrm{dmft}$ [24], especially in countries where the overall decay experience is low [24, 25]. $\mathrm{SiC}$ resolves the problem related to skewed caries distribution when using the $\mathrm{dmft} / \mathrm{dmfs}$. Its use, however, needs to be complemented with other relevant information to enhance planning for caries management [26].

Overall, despite the limitations of the identified indices, they are invaluable for population-level caries management. We provide an age-specific report on ECC experience in children 6-71-months-old resident in a semi-urban area of Nigeria using these indices thereby harnessing their potential to develop an epidemiological profile of ECC in Nigeria.

Past studies on the profile of ECC in Nigeria had reported on the prevalence $[27,28]$ and risk factors for ECC in different communities in the country [27-30]. Caries are affected by multiple factors including the caries risk behaviors of individuals. Caries risk behaviors include the regularity of toothbrushing, frequency of consumption of cariogenic diet, use of fluoridated toothpaste, and the use of preventive dental services for preventive dental care [31]. None of these studies conducted to date had reported on age group-specific risk indicators of ECC in Nigeria. A more granular detail on the severity of ECC measured using the $\mathrm{dmft} / \mathrm{dmfs}$, ICDAS, pufa, and the $\mathrm{SiC}$ indices will enhance the planning for specific age group intervention. We also report on age-specific ECC risk indicators of the study population.

\section{Methods}

The data for this study was extracted from that of a primary cross-sectional study conducted to determine the association between maternal psychological factors and ECC in children 6-71 months old. Clinical examination and household survey data were collected between December 2018 and January 2019 in the Ile-Ife local government area of Osun State, Nigeria.

The methodology for the survey had been described in prior publications [32-36]. The primary study required 
a minimum sample of 1439 computed by using a prevalence of $6.6 \%$, a margin of error of $5 \%$, and a confidence level of $95 \%$. The sample was recruited from households distributed proportionately across the 11 political wards. In each political ward, enumeration centers were randomly selected from the north, south, east, west and central axis of each ward to obtain samples representative of the local government area. A total of 70 of the 700 enumeration centres in the local government areas were randomly selected. At each of the enumeration sites, every other household on each street was eligible for recruitment of the child. A child was recruited from each household. Children recruited from each household were less than 6 years of age, living with a caregiver, present at the time of the survey, had at least one tooth erupted into the mouth, and with caregiver's consent to participate in the study. In any household where more than one child was eligible to participate, the study participant was selected by simple ballot. Whenever a household declined to participate, it was substituted with the next eligible household. Children who had chronic medical conditions requiring prolonged use of sweetened medications and those with medical conditions that increased their risk of ECC were excluded from the study.

The oral examinations were conducted by five calibrated dentists using the $\mathrm{dmft}$, dmfts, pufa, and ICDAS indices. The Kappa statistic for intra-examiner agreement ranged from 0.80 to 0.92 . The inter-examiner agreement between each of the dentists and the trainer ranged from 0.80 to 0.89 . The inter-examiner agreement for pairs of the five dentists ranged from 0.82 to 0.91 . The children were examined either sitting on a chair or their mother's lap. Illumination was through the use of natural daylight without the use of a magnifying lens and air drying. Visual examinations were performed with plane dental mirrors. No radiographs were used.

\section{dmf indices}

The dmf index was determined using the World Health Organization criteria at the cavitation level [7]. The $\mathrm{dmft}$ score was obtained by adding the $\mathrm{d}, \mathrm{m}$, and $\mathrm{f}$ scores for each child at the tooth level while the dmfs index was the sum of the $d, m$, and $f$ scores at the tooth surface level.

\section{The pufa index}

The 'p' indicated pulpal involvement when the opening of the pulp chamber was visible or when coronal structures had been destroyed by caries and only roots or root fragments were left. No probing was used to diagnose pulpal involvement. The ' $u$ ' indicated ulceration due to trauma from sharp pieces of tooth and was recorded when sharp edges of a dislocated tooth with pulpal involvement or root fragments caused traumatic ulceration of surrounding soft tissues, e.g. tongue or buccal mucosa. The ' $\mathrm{f}$ ' indicated fistula and was scored when a pus-releasing sinus tract related to a tooth with pulpal involvement was present. The 'a' indicated abscess and was scored when a pus containing swelling related to a tooth with pulpal involvement was present. To arrive at a pufa score, the number of carious primary teeth with pulpal involvement, carious teeth with ulceration, and carious teeth with fistula and with abscess was determined and summed for each child [18].

\section{The ICDAS index}

Caries status was assessed with the ICDAS II index [31]. The ICDAS II scores for dental caries diagnosis included (0) Sound tooth; (1) First visual change in enamel; (2) Distinct visual change in enamel; (3) Localized enamel breakdown; (4) Underlying dark shadow from dentine; (5) Distinct cavity with visible dentine; (6) Extensive distinct cavity with visible dentine [37]. The severity of ECC was measured with ICDAS II using three different thresholds: ICDAS-1, identifying any caries lesion at any stage $\left(\mathrm{d}^{1-6}\right)$; ICDAS-2, including non-cavitated lesions $\left(\mathrm{d}^{1-2}\right)$, and ICDAS -3 : including advanced lesions $\left(\mathrm{d}^{3-6}\right)$. In place of compressed air, cotton rolls were used to dry the tooth surfaces like was done in a prior study outside the clinic [38]. No radiographs were taken. The teeth were examined after removing dental plaque from tooth surfaces and dried using gauze pads. The mesial, distal, buccal, lingual, and occlusal surfaces (where present) were examined.

\section{$\mathrm{SiC}$ index}

The $\mathrm{SiC}$ Index is the mean dmft of one-third of the study group with the highest caries score. To calculate the $\mathrm{SiC}$ index for each age group, we sorted each age group according to their $\mathrm{dmft}$, selected one-third of the children in each age group with the highest $\mathrm{dmft}$, and calculated the mean $\mathrm{dmft}$ for per age group [39].

\section{ECC risk indicators}

The ECC risk indicators of each child were assessed using the tool developed by Khami et al. [31] and adapted for use with children, adolescents, and young people in Nigeria [36, 38, 40,41]. Information was generated on the frequency of tooth brushing, consumption of refined carbohydrate in-between meals, daily use of fluoridated toothpaste, and dental service utilization in the 12 months preceding the study. Information was also obtained about a child's sex and age in years which was classified for analysis into one-year age bins.

Respondents were asked to indicate the frequency of consuming sugar-containing snacks or drinks in-between 
meals using the following options-'about three times a day or more, 'about twice a day', 'about once a day,' 'occasionally', 'not every day', 'rarely', or 'never between meals'. Responses were dichotomized into 'three times a day or more' and 'less than three times a day'. Consumption of refined carbohydrates (sugar containing snacks or drinks) in-between-meals three times a day or more was classified as an ECC risk indicator [28, 36, 42].

Respondents were also asked to indicate the time of their last dental check-up as follows - within the last 6 months, more than 6 months to one year ago, more than 1-2 years ago, more than $2-5$ years ago, more than 5 years, never, do not remember. Respondents who chose the options within the last 6 months and more than 6 months to one year ago were classified as having undertaken ECC preventive dental care while those who chose the other options were classified as having ECC risk indicator [38, 43].

Respondents were asked to indicate the frequency of their use of fluoridated toothpaste when tooth brushing using the following options-'always', 'quite often', 'seldom,' 'not at all'. Respondents who answered 'always, were classified as having undertaken ECC preventive dental care and all others were classified as having ECC risk indicator [38].

Respondents were also asked to indicate the frequency of tooth brushing using the following response options'irregularly or never', 'once a week', 'a few (2-3) times a week', 'once a day', and 'more than once a day'. Responses were further dichotomized into 'more than once a day', considered good ECC preventive practice versus 'once a day or less' which was considered an ECC risk indicator $[38,44]$.

\section{Data analysis}

Age was categorised into 6-11-months-old, 12-23-months-old, 23-35-months-old, 35-47-months old; 48-59-months-old and 60-71-months old. The mean $\mathrm{dmft}$, dmfs, and pufa scores for each age group and each tooth type were computed. The prevalence of ECC was calculated as the proportion of participants with ICDAS- $1\left(\mathrm{~d}^{1-6}\right)$ greater than zero. The percentage of children with ECC was determined according to two ICDAS II thresholds (ICDAS-2 $\left(\mathrm{d}^{1-2}\right)$, and ICDAS-3 $\left(\mathrm{d}^{3-6}\right)$ ) for non-cavitated and cavitated carious lesions respectively. The differences in mean $\mathrm{dmft}$, dmfs, pufa scores, and the percentages of children with ICDAS 1, 2, and 3 scores among age groups were computed using ANOVA and Chi test respectively.

The prevalence of each ECC risk indicator-frequency of tooth brushing, consumption of refined carbohydrate in-between-meals, daily use of fluoridated toothpaste, and dental service utilization in the 12 months preceding the study-was computed for each age group. The differences in the prevalence of the ECC risk indicators among age groups were also compared using the Chi test.

Linear regression analysis was done to identify risk indicators for the ECC SiC index. Statistical analyses were conducted with Stata/SE 14.0 for Windows. The significance level was set at $p<0.05$.

\section{Results}

Table 1 provides an overview of the ECC profile of the 1549 study participants. ECC prevalence using ICDAS $\left(\mathrm{d}^{1-6}\right)$ was $4.7 \%-73$ of the 1549 children examined had ECC: 45 (2.9\%) had non-cavitated lesions (ICDAS d ${ }^{1-2}$ ) and $43(2.8 \%)$ had cavitated lesions (ICDAS d $\left.{ }^{3-6}\right)$. There

Table 1 ICDAS dmft, dmfs, pufa and SiC index scores by age of children 6-71-months-old in lle-Ife, Nigeria (N=1549)

\begin{tabular}{|c|c|c|c|c|c|c|c|c|c|}
\hline Age & $\begin{array}{l}\text { No. of } \\
\text { children } \\
\text { examined } \\
n(\%)\end{array}$ & $\begin{array}{l}\text { ICDAS O n } \\
\text { (\%) }\end{array}$ & $\begin{array}{l}\text { ICDAS 1-2 } \\
\text { n (\%) }\end{array}$ & $\begin{array}{l}\text { ICDAS 3-6 } \\
\text { n (\%) }\end{array}$ & $\begin{array}{l}\text { ICDAS 1-6 } \\
\text { n (\%) }\end{array}$ & $\begin{array}{l}\text { Mean (SD) } \\
\text { dmft }\end{array}$ & $\begin{array}{l}\text { Mean (SD) } \\
\text { dmfs }\end{array}$ & $\begin{array}{l}\text { Mean (SD) } \\
\text { pufa }\end{array}$ & SiC index \\
\hline 6-11 months & $125(8.1)$ & $123(98.4)$ & $1(0.8)$ & $1(0.8)$ & $2(1.6)$ & $0.03(0.36)$ & $0.11(0.89)$ & $0.0(0.0)$ & 4 \\
\hline $\begin{array}{l}12- \\
23 \text { months }\end{array}$ & $244(15.8)$ & $237(97.1)$ & $5(2.1)$ & $3(1.2)$ & $7(2.9)$ & $0.12(1.16)$ & $0.29(3.24)$ & $0.05(0.77)$ & 6 \\
\hline $\begin{array}{l}24- \\
35 \text { months }\end{array}$ & $262(16.9)$ & $246(93.9)$ & $14(5.3)$ & $6(2.3)$ & $16(6.1)$ & $0.27(1.54)$ & $0.36(2.53)$ & $0.04(0.50)$ & 4 \\
\hline $\begin{array}{l}36- \\
47 \text { months }\end{array}$ & $355(22.9)$ & $340(55.8)$ & $9(2.5)$ & $11(3.1)$ & $15(4.2)$ & $0.14(0.80)$ & $0.22(1.43)$ & $0.05(0.47)$ & 3 \\
\hline $\begin{array}{l}48- \\
59 \text { months }\end{array}$ & $335(21.6)$ & $315(94.0)$ & $9(2.7)$ & $14(4.2)$ & $20(6.0)$ & $0.10(0.47)$ & $0.20(0.96)$ & $0.04(0.29)$ & 2 \\
\hline $\begin{array}{l}60- \\
71 \text { months }\end{array}$ & $228(14.7)$ & $215(94.3)$ & $7(3.1)$ & $8(3.5)$ & $13(5.7)$ & $0.07(0.45)$ & $0.21(1.12)$ & $0.02(0.21)$ & 2 \\
\hline Total & $1549(100.0)$ & 1476 (95.3) & $45(2.9)$ & $43(2.8)$ & $73(4.7)$ & $0.13(0.92)$ & $0.24(1.91)$ & $0.04(0.46)$ & 3 \\
\hline$p$-values & & 0.189 & 0.149 & 0.209 & 0.189 & $0.12 ¥$ & $0.846 ¥$ & $0.89 ¥$ & \\
\hline
\end{tabular}

IChi-square, $¥$ ANOVA 
was no significant difference in the prevalence of noncavitated (ICDAS d $\left.{ }^{1-2}\right)(p=0.137)$ and cavitated (ICDAS $\left.\mathrm{d}^{3-6}\right)(p=0.204)$ lesions among the 6 age groups.

The mean (SD) dmft for all age groups was $0.13(0.92)$ and the mean (SD) dmfs was 0.24 (1.91). The dmft and dmfs scores were highest among the 24-35-months-old age group. There were no significant differences in the mean dmft $(p=0.115)$ and mean $\mathrm{dmfs}(p=0.846)$ scores among the different age groups.

The mean (SD) pufa score was 0.04 (0.46) with scores ranging from 0 in 6-11-months-olds to 0.05 among 12-23-months-olds and 36-47-months-old children. Though there was no age-related pattern observed in ECC related complications as reflected by the pufa scores, we noticed less severity in the age 48-59-monthsold group to the 60-71-months-old group. There was no significant difference in the severity of complications among the age groups $(p=0.891)$.

The $\mathrm{SiC}$ score also increased from 4 in 6-11-monthsold to 6 in 12-23-months-old and thereafter, the score decreased to 4 in 24-35-months old to 2 in 48-59-months-old and 60-71-months old respectively. The $\mathrm{SiC}$ score was higher than the group mean score in children 6-47-months-old.
Table 2 highlights the details of the $\mathrm{dmft}$, $\mathrm{dmfs}$ and pufa for each tooth. The teeth with the topmost mean (SD) dmft scores were \#51 (0.014 (0.118)) followed by \#85, \#61, \#52 (0.012 (0.11), and \#84, \#62 (0.011 (0.104)). The lower canines and the lower incisors had the least scores (\#73, \#53, \#81, \#63, \#72, \#83, and \#82 respectively). The teeth with the highest mean (SD) dmfs scores were \#85 and \#61 followed by \#54, \#84, \#74 and \#64. The lower left and upper right canines, and the lower central incisors have the least scores (\#73, \#53, $\# 81, \# 71$ respectively). The teeth with the highest pufa scores were \#64, \#85, \#61 and \#75; while the upper canines and lower central incisors did not have complications though they had carious lesions.

Table 3 shows the age-specific distribution of ECC risk indicators in the study participants. The proportion of children who consumed refined carbohydrate in-between-meals three times a day or more, utilized the dental service in the 12 months preceding the study, used fluoridated toothpaste daily, and brushed their teeth more than once a day was $18.9 \%, 5.8 \%, 90.8 \%$, and 93.2\% respectively. Significantly fewer children consumed refined carbohydrate in-between-meals three times a day or more among those aged 6-11-monthsold than other age groups $(p<0.001)$. Also, significantly

Table 2 The mean and standard deviation of the dmft, dmfs, and pufa scores by tooth type in 6-11-months-old children in Ile-Ife, Nigeria $(N=1549)$

\begin{tabular}{|c|c|c|c|c|c|c|}
\hline \multirow[t]{2}{*}{ Tooth } & \multicolumn{2}{|l|}{ Dmft } & \multicolumn{2}{|l|}{ Dmfs } & \multicolumn{2}{|l|}{ Pufa } \\
\hline & Mean & SD & Mean & SD & Mean & SD \\
\hline 51 & 0.014 & 0.118 & 0.018 & 0.168 & 0.001 & 0.025 \\
\hline 52 & 0.012 & 0.110 & 0.016 & 0.188 & 0.003 & 0.051 \\
\hline 53 & 0.002 & 0.044 & 0.003 & 0.062 & 0.000 & 0.000 \\
\hline 54 & 0.009 & 0.095 & 0.021 & 0.236 & 0.003 & 0.051 \\
\hline 55 & 0.004 & 0.062 & 0.009 & 0.172 & 0.003 & 0.051 \\
\hline 61 & 0.012 & 0.110 & 0.023 & 0.237 & 0.005 & 0.111 \\
\hline 62 & 0.011 & 0.104 & 0.015 & 0.160 & 0.001 & 0.036 \\
\hline 63 & 0.002 & 0.044 & 0.005 & 0.116 & 0.000 & 0.000 \\
\hline 64 & 0.008 & 0.088 & 0.019 & 0.243 & 0.006 & 0.134 \\
\hline 65 & 0.005 & 0.067 & 0.008 & 0.129 & 0.001 & 0.025 \\
\hline 71 & 0.003 & 0.051 & 0.003 & 0.067 & 0.000 & 0.000 \\
\hline 72 & 0.002 & 0.044 & 0.005 & 0.098 & 0.000 & 0.000 \\
\hline 73 & 0.001 & 0.036 & 0.001 & 0.025 & 0.001 & 0.025 \\
\hline 74 & 0.008 & 0.091 & 0.019 & 0.239 & 0.002 & 0.044 \\
\hline 75 & 0.010 & 0.098 & 0.018 & 0.218 & 0.004 & 0.062 \\
\hline 81 & 0.002 & 0.044 & 0.003 & 0.062 & 0.000 & 0.000 \\
\hline 82 & 0.002 & 0.044 & 0.007 & 0.141 & 0.001 & 0.025 \\
\hline 83 & 0.002 & 0.044 & 0.007 & 0.167 & 0.001 & 0.025 \\
\hline 84 & 0.011 & 0.104 & 0.019 & 0.218 & 0.003 & 0.051 \\
\hline 85 & 0.012 & 0.110 & 0.023 & 0.225 & 0.005 & 0.114 \\
\hline Total & 0.131 & 0.920 & 0.241 & 1.901 & 0.037 & 0.458 \\
\hline
\end{tabular}


Table 3 Proportion of children 6-71-months-old children in lle-lfe, Nigeria with caries risk behaviors by age group ( $N=1549)$

\begin{tabular}{lllll}
\hline Age & $\begin{array}{l}\text { Intake of refined carbohydrate in-between- } \\
\text { meals three times a day or more } \mathbf{n}(\%)\end{array}$ & $\begin{array}{l}\text { Dental service utilization in the } \\
\text { past } \mathbf{1 2} \text { months } \mathbf{n}(\%)\end{array}$ & $\begin{array}{l}\text { Use of fluoridated } \\
\text { toothpaste } \mathbf{n}(\%)\end{array}$ & $\begin{array}{l}\text { Toothbrushing more } \\
\text { than once a day } \mathbf{n}(\%)\end{array}$ \\
\hline $6-11$ & $8(6.4)$ & $8(6.4)$ & $79(63.2)$ & $118(94.4)$ \\
$12-23$ & $32(13.1)$ & $13(5.3)$ & $218(89.3)$ & $228(93.4)$ \\
$24-35$ & $40(15.3)$ & $15(5.7)$ & $233(88.9)$ & $236(90.1)$ \\
$36-47$ & $47(13.2)$ & $28(7.9)$ & $338(95.2)$ & $331(93.2)$ \\
$48-59$ & $41(12.2)$ & $16(4.8)$ & $322(96.1)$ & $319(95.2)$ \\
$60-71$ & $43(18.9)$ & $10(4.4)$ & $217(95.2)$ & $211(92.5)$ \\
Total & $211(18.9)$ & $90(5.8)$ & $1407(90.8)$ & $1443(93.2)$ \\
p value & $<0.001$ & 0.482 & $<0.001$ & 0.251
\end{tabular}

fewer children used fluoridated toothpaste among those aged 6-11-months-old than other age groups $(p<0.001)$. There was no significant difference in the proportion of children who utilized the dental service in the 12 months preceding the study $(p=0.482)$ and the proportion of children who brushed their teeth more than once a day $(p=0.251)$ by age group.
Table 4 shows the risk indicators for the $\mathrm{SiC}$ score in the different age groups. Sex, intake of refined carbohydrate in-between-meals three times a day, use of fluoridated toothpaste, and dental service utilization were not significantly associated with $\mathrm{SiC}$ scores in any of the six age groups. The only significant risk indicator was tooth brushing more than once a day. Children

Table 4 Logistic regression analysis for caries risk behaviors associated with ECC for 6-71-months-old children in Ile-Ife, Nigeria with caries risk behaviors by age group $(\mathrm{N}=1549)$

\begin{tabular}{|c|c|c|c|c|c|c|}
\hline \multirow[t]{4}{*}{ Age } & \multicolumn{6}{|l|}{ SiC index } \\
\hline & 6-11 months & $12-23$ months & 24-35 months & $36-37$ months & 48-59 months & $60-71$ months \\
\hline & AOR $(95 \% \mathrm{Cl})$ & AOR $(95 \% \mathrm{Cl})$ & AOR $(95 \% \mathrm{Cl})$ & AOR $(95 \% \mathrm{Cl})$ & AOR $(95 \% \mathrm{Cl})$ & AOR (95\% Cl) \\
\hline & $p$ value & $p$ value & $p$ value & $p$ value & $p$ value & $p$ value \\
\hline \multicolumn{7}{|l|}{ Sex } \\
\hline Male & & & 1.00 & 1.00 & 1.00 & 1.00 \\
\hline \multirow[t]{2}{*}{ Female } & & - & 0.75 & 1.50 & 0.75 & 1.39 \\
\hline & - & & $(0.16-3.56)$ & $(0.51-4.42)$ & $(0.20-2.80)$ & $(0.09-22.59)$ \\
\hline \multicolumn{7}{|c|}{$\begin{array}{l}\text { Intake of refined carbohydrate in-between- } \\
\text { meals three times a day or more }\end{array}$} \\
\hline No & & - & 1.00 & 1.00 & 1.00 & - \\
\hline \multirow[t]{2}{*}{ Yes } & - & & 0.95 & 4.21 & 2.94 & \\
\hline & & & $(0.11-8.43)$ & $(1.56-11.37)$ & $(0.69-12.49)$ & \\
\hline \multicolumn{7}{|c|}{ Dental service utilization in the past 12 months } \\
\hline No & & & & 1.00 & & \\
\hline \multirow[t]{2}{*}{ Yes } & - & - & - & 0.86 & - & - \\
\hline & & & & $(0.11-6.97)$ & & \\
\hline \multicolumn{7}{|c|}{ Use of fluoridated toothpaste } \\
\hline No & & 1.00 & 1.00 & 1.00 & & \\
\hline \multirow[t]{2}{*}{ Yes } & - & 0.08 & 0.17 & 0.29 & - & - \\
\hline & & $(0.004-1.37)$ & $(0.03-01.01)$ & $(0.05-1.54)$ & & \\
\hline \multicolumn{7}{|c|}{ Toothbrushing more than once a day } \\
\hline No & & & 1.00 & 1.00 & 1.00 & \\
\hline \multirow[t]{2}{*}{ Yes } & - & - & 0.44 & 3.55 & 0.11 & - \\
\hline & & & $(0.04-4.28)$ & $(0.28-45.21)$ & $(0.02-0.61)^{*}$ & \\
\hline$R^{2}$ & & 0.13 & 0.06 & 0.08 & 0.08 & 0.02 \\
\hline
\end{tabular}

${ }^{*} p<0.05$ 
aged 48-59 months who brushed their tooth more than once a day had significantly lower $\mathrm{SiC}$ score when compared to children brushed their tooth once a day or more $(\mathrm{B}=0.11 ; 95 \% \mathrm{CI} 0.02,0.61)$.

\section{Discussion}

This study produces the first population-level information on the severity of ECC and the prevalence of associated complications in Nigeria. It is also the first study to measure the prevalence of ECC in Nigeria using the ICDAS and $\mathrm{SiC}$ index. The results indicate that the overall prevalence of cavitated and non-cavitated carious lesion in the study population was low; there was almost a doubling of the ECC prevalence by age 12-23 months and a four-fold increase (a three-fold increase in cavitated and non-cavitated lesions) by age 24-35-monthsold when compared to those age 6-11-months-old. The $\mathrm{SiC}$ score was also highest at age 12-23 months, and children 6-37-months old had higher $\mathrm{SiC}$ scores than the $\mathrm{SiC}$ score for the study population. We also observed that ECC complications occurred at all ages except for those below 1-year-old. The only risk indicator for ECC was toothbrushing, and this was only significantly associated with lower $\mathrm{SiC}$ in children age 48-59-months. The teeth worst affected by caries were teeth \#85 and \#61 (teeth reaching the three topmost $\mathrm{dmft}, \mathrm{dmfs}$, and pufa scores).

One of the strengths of the study is that it provides details about age-specific risk indicators for ECC in the study population. It, therefore, allows for planning agetargeted interventions. We found that there are subgroups of pre-school children with high levels of ECC which require public health response. Though those aged 24-35-months old appear to be at a critical year when the $\mathrm{dmft}$, dmfs peaks, the ECC caries crisis seems to have started evolving by age 12-23-months-old where we find the highest $\mathrm{SiC}$ score and a doubling of the caries prevalence. This may indicate that the weaning diets of these children may be high-caries risk diets. There is little known about the weaning diet of the population, but the finding of this study suggests that the sugar content of the diet may be a cause of concern for ECC risk. Though a large population of mothers in the study community breastfed their children up to 24 months [45], the duration of breastfeeding was not identified as a risk indicator for ECC in the study population [29, 42]. A prior study conducted in pre-school children in Lagos, Nigeria indicated, however, that breastfeeding longer than 18 months and exclusive breastfeeding was associated with higher dmft [46].

The study finding indicated that caries prevention practices for children in this population need to start by age $6-11$-months when the cariogenic diet is low. This preventive practice should include the use of fluoridated toothpaste and twice-daily toothbrushing though this study did not identify them as risk indicators for the population worst affected by ECC. A prior study conducted in the study environment indicated that the combination of the use of fluoridated toothpaste and twice-daily tooth brushing was the most effective caries prevention measure for children in the study environment with both primary and permanent dentition [47]. ECC prevention messages may be useful in this context and maybe reinforced using multiple possible settings such as the immunization clinics with emphasis on effective tooth brushing more than once a day [48]. These measures can help reduce the increase by age in the prevalence of cavitated and non-cavitated caries and the development of ECC complications observed in this study.

Also, unlike the recommendation made by El Tantawi et al. [49] on the need for epidemiological surveys on ECC to report separately on children 2 years and below versus children 3-5-years-old, we believe that the epidemiological profile of ECC for children 1-year-old and below should be reported distinctly from that of children older than 1-year-olds. We noticed that a difference in ECC profile starts to develop after the age of 1-year indicating the need for ECC prevention programs to be instituted for children in the study population earlier than one year. ECC prevention programs initiated during the antenatal periods were highly successful $[50,51]$, with those initiated at the age of one year having the greatest impact [50].

In addition, the risk indicators associated with ECC severity differed for each age group. While the intake of refined carbohydrates in-between-meals was associated with a higher $\mathrm{dmft}$ score for all age groups except those 60-71-months-old, it was only significantly associated with the dmft score in children 24-35-months-old. The use of fluoridated toothpaste also was associated with lower $\mathrm{dmft}$ scores for all age groups and significantly so for children 24-35-months-old. The significant indicator associated with lower $\mathrm{dmft}$ in children 48-59-monthsold was tooth brushing twice daily or more. Past studies had indicated that consumption of refined carbohydrates and poor oral hygiene were risk indicators for ECC in this study population [28]. What the results of this study suggest is that efforts to control the consumption of refined carbohydrates in-between-meals three times a day or more to reduce the risk of high $\mathrm{dmft}$ scores need to start before 24 months. On the other hand, the emphasis on good oral hygiene as a prevention strategy for ECC may be more strategic at an age later than $24-35$-months. This study, for the first time, identified that the use of fluoridecontaining toothpaste can protect against high $\mathrm{dmft}$ in contrast to a past ECC study in the study environment 
which was not able to find this association [28]. Thus, an age-specific approach for tailoring ECC risk reduction strategies in communities with low ECC prevalence may be effective in planning for the elimination of ECC in these communities.

Also, like a past study [52], we report a high prevalence and higher severity of ECC in the upper central incisors and lower molar teeth. The lower molar teeth seem to be more prone to caries complications with implications for associated pain, negative impact on growth and development [53], and negative impact on the quality of life of both the child and the mother [54]. The importance of this for the developing child is enormous. The impact of caries-associated pain on children's social interactions and psychological development was previously highlighted [55]. Public health intervention is therefore required in this study population to mitigate the impact of ECC and address its burden in toddlers in this population. These interventions include promoting access of children to oral health care services by their first birthday or as soon as the first tooth erupts [43]. Also, early intervention with pregnant mothers during the perinatal visits may help reduce the risk of ECC $[51,56]$.

Finally, preventive care for children should include the use of topical fluoride and fissure sealants because the teeth worst affected by ECC are \#85 and \#61. Topical fluoride is essential to prevent smooth surface caries to which the upper central incisors are predisposed [57]. Fissure sealants are of value in preventing fissure caries for which the primary second molar are predisposed through the evidence of its benefits in preventing or arresting non-cavitated occlusal caries in the primary molars are still not well established [58].

This study has few limitations. Several studies have reported the limitation associated with the use of the $\mathrm{dmft}$ index for caries assessment. This includes high inter-observer bias and variability [59]. Our use of the ICDAS helps us to increase the validity of our caries profile as the ICDAS is more sensitive to identifying non-cavitated lesions than the $\mathrm{dmft}$ and $\mathrm{dmfs}$ [57]. The inter-examiner reliability for this study is also high therefore reducing the risk of examiner variability. In addition, the cross-sectional design of the study cannot support causality and can only suggest associations that need to be further addressed in longitudinal studies. Despite these limitations, the study provides new information and a profile of ECC in a population with low ECC prevalence.

\section{Conclusion}

The study finding suggests that there are age groupspecific risk indicators of ECC; and for this study population, tooth brushing once a day or less may be a risk factor for children age 48-59-months. Though the ECC prevalence is low in the study population, the age group with the worst ECC experience was children 24-35-months-old. Interventions to reduce the risk of ECC and its sequelae should begin by 12 months of age at the latest, with the focus being on reinforcing the use of a low cariogenic diet and promoting the use of fluoridated toothpaste. For children 24-35-monthsold, the application of topical fluoride and fissure sealants should be included as part of the caries prevention interventions. Oral health policies to push and monitor this oral health care paradigm is needed for the study population.

\section{Abbreviations}

dmft: Decayed, missing, and filled tooth; dmfs: Decayed, extracted, and filled tooth surfaces; ECC: Early childhood caries; ICDAS: International caries detection and assessment system; pufa: Pulp, ulceration, fistula and abscesses; SiC: Significant caries.

\section{Acknowledgements}

We acknowledge and thank the study participants for the contributions they made to generating new knowledge. We also thank Dr Micheal Alade who was involved with Data collection and Dr Elizabeth Oziegbe who contributed financially to the conduct of the household survey.

\section{Authors' contributions}

The project was conceptualized by MOF. The data for the research was collected by MOF. ABO conducted the data analysis.AA, MET and TLF read and contributed to several versions of the manuscript. All authors read and approved the final manuscript.

\section{Funding}

No grant supports this study. The authors made the needed financial contributions for the conduct of the study.

\section{Availability of data and materials}

Study-related data and materials are accessible on request from the lead author.

\section{Declarations}

\section{Ethics approval and consent to participate}

Ethics approval for the study was obtained from the Health Research Ethics Committee of the Obafemi Awolowo University Teaching Hospitals' Complex in Ile-Ife (IRB/IEC/0004553 and NHREC/27/02/2009a). Permission for conducting the study was also obtained from the Ife Central Local Government Area. Consent was obtained from mothers of children who participated in the study after they were duly informed about the objectives of the study, risks and benefits, voluntary nature of study participation, and freedom to withdraw from the study at any time. Written consent was obtained from all participants. No identifier was collected for each respondent.

\section{Consent for publication}

Not applicable.

\section{Competing interests}

Morenike Oluwatoyin Folayan and Maha El Tantawi are both sectional editors with the BMC Oral Health.

\section{Author details}

${ }^{1}$ Department of Child Dental Health, Obafemi Awolowo University, Ile-Ife, Nigeria. ${ }^{2}$ Innovative Aid, Abuja, Nigeria. ${ }^{3}$ Department of Pediatric Dentistry 
and Dental Public Health, Faculty of Dentistry, Alexandria University, Alexandria, Egypt. ${ }^{4}$ San Diego State University, San Diego, USA. ${ }^{5}$ Department of Preventive Dentistry, Lagos State University College of Medicine, Ikeja, Lagos State, Nigeria.

Received: 14 May 2021 Accepted: 15 August 2021 Published online: 23 August 2021

\section{References}

1. Marcenes W, Kassebaum NJ, Bernabe E, Flaxman A, Naghavi M, Lopez A, et al. Global burden of oral conditions in 1990-2010: a systematic analysis. J Dent Res. 2013;2013(92):592-7.

2. Feitosa S, Colares V, Pinkham J. The psychosocial effects of severe caries in 4-year-old children in Recife, Pernambuco. Brazil Cad Saude Publica. 2005;21(5):1550-6.

3. Anil S, Anand P. Early childhood caries: prevalence, risk factors, and prevention. Front Pediatr. 2017;5(157):1-5.

4. Gomes MC, Pinto-Sarmento TC, Costa EM, Martins CC, Granville-Garcia AF, Paiva SM. Impact of oral health conditions on the quality of life of preschool children and their families: a cross-sectional study. Health Qual Life Outcomes. 2014;12:55.

5. Veiga $\mathrm{N}$, Coelho I. The importance of epidemiology in dental medicine. J Dent Oral Health. 2015;1(4):21.

6. Klein H, Palmer CE, Knutson JW. Studies on dental caries. Public Health Rep. 1938;53:751-65.

7. World Health Organization. Oral Health Surveys-Basic Methods. 4. Geneva:WHO; 1997.

8. Baker SR, Foster Page L, Thomson WM, Broomhead T, Bekes K, Benson PE, et al. Structural determinants and children's oral health: a cross-national study. J Dent Res. 2018;97(10):1129-36.

9. Broadbent JM, Thomson WM. For debate: problems with the DMF index pertinent to dental caries data analysis. Commun Dent Oral Epidemiol. 2005;33(6):400-9.

10. Bandyopadhyay D. From mouth-level to tooth-level DMFS: conceptualizing a theoretical framework. J Dent Oral Craniofac Epidemiol. 2013;1(1):3-8.

11. Cappelli DP, Mobley CC. Prevention in clinical oral health care. St. Louis, Mo: Mosby Elsevier; 2008.

12. Ismail Al, Sohn W, Tellez M, Amaya A, Sen A, Hasson H, Pitts NB. The international caries detection and assessment system (IDAS): an integrated system for measuring dental caries. Commun Dent Oral Epidemiol. 2007;35(3):170-8

13. Bhumireddy JR, Challa R, Mallineni SK, Nuvvula S. Comparison of international caries detection and assessment system and digital radiographs for detecting occlusal dental caries: an in vivo study. Eur I Gen Dent. 2018;7:61-5.

14. Dikmen B. Icdas II criteria (international caries detection and assessment system). J Istanb Univ Fac Dent. 2015;49(3):63-72.

15. Broadbent JM, Thomson WM. For debate: problems with the DMF index pertinent to dental caries data analysis. Commun Oral Dent Epidemiol. 2005;33(6):400-9.

16. Braga MM, Ekstrand KR, Martignon S, Imparato JC, Ricketts DN, Mendes FM. Clinical performance of two visual scoring systems in detecting and assessing activity status of occlusal caries in primary teeth. Caries Res. 2010;44(3):300-8.

17. Kühnisch J, Berger S, Goddon I, Senkel H, Pitts N, Heinrich-Weltzien R. Occlusal caries detection in permanent molars according to WHO basic methods, ICDAS II and laser fluorescence measurements. Commun Dent Oral Epidemiol. 2008;36(6):475-84.

18. Monse $B$, Heinrich-Weltzien $\mathrm{R}$, Benzian $\mathrm{H}$, Holmgren $\mathrm{C}$, van Palenstein HW. PUFA - an index of clinical consequences of untreated dental caries. Commun Dent Oral Epidemiol. 2010;38:77-82.

19. Mehta A. Comprehensive review of caries assessment systems developed over the last decade. RSBO (Online). 2012; 9(3)

20. Oziegbe EO, Esan TA. Prevalence and clinical consequences of untreated dental caries using PUFA index in suburban Nigerian school children. Eur Arch Paediatr Dent. 2013;14(4):227-31.
21. Folayan MO, Chukwumah NM, Onyejaka N, Adeniyi AA, Olatosi OO. Appraisal of the national response to the caries epidemic in children in Nigeria. BMC Oral Health. 2014;14:76.

22. Abanto J, Carvalho TS, Mendes FM, Wanderley MT, Bönecker M, Raggio DP. Impact of oral diseases and disorders on oral health-related quality of life of preschool children. Commun Dent Oral Epidemiol. 2011;39(2):105-14

23. Department of Health and Human Services. Water fluoridation-community information. Victorian State Government, Melbourne; 2017.

24. Jürgensen N, Petersen P. Promoting oral health of children through schools-Results from a WHO global survey 2012. Commun Dent Health. 2013;30(4):204-18.

25. Li J, Fan W, Zhou Y, Wu L, Liu W, Huang S. The status and associated factors of early childhood caries among 3- to 5-year-old children in Guangdong, Southern China: a provincial cross-sectional survey. BMC Oral Health. 2020;20(1):265.

26. Campus G, Solinas G, Maida C, Castiglia P. The "Significant Caries Index" (SiC): a critical approach. Oral Health Prev Dent. 2003;1(3):171-8.

27. Iyun OI, Denloye OO, Bankole OO, Popoola BO. Prevalence and pattern of early childhood caries in Ibadan, Nigeria. Afr J Med Med Sci. 2014;43(3):239-44.

28. Folayan MO, Kolawole KA, Oziegbe EO, Oyedele T, Oshomoji OV, Chukwumah NM, Onyejaka N. Prevalence, and early childhood caries risk indicators in preschool children in suburban Nigeria. BMC Oral Health. 2015;15:72.

29. Folayan MO, Arije O, El Tantawi M, Kolawole KA, Obiyan M, Arowolo O, Oziegbe EO. Association between early childhood caries and malnutrition in a sub-urban population in Nigeria. BMC Pediatr. 2019;19(1):433.

30. Folayan MO, El Tantawi M, Oginni AB, Alade M, Adeniyi A, Finlayson TL. Malnutrition, enamel defects, and early childhood caries in preschool children in a sub-urban Nigeria population. PLOS ONE. 2020;15(7):e0232998.

31. Khami MR, Virtanen Jl, Jafarian M, Murtomaa H. Oral health behaviour of Iranian dental school educators. Oral Health Prev Dent. 2006;4(4):265-71.

32. Folayan MO, Alimi P, Alade MO, Tantawi ME, Adeniyi AA, Finlayson TL. Validation of maternal report of early childhood caries status in lle-lfe, Nigeria. BMC Oral Health. 2020;20(1):336.

33. Folayan MO, El Tantawi M, Oginni A, Adeniyi A, Alade M, Finlayson TL. Psychosocial, education, economic factors, decision-making ability, and caries status of mothers of children younger than 6 years in suburban Nigeria. BMC Oral Health. 2020;20(1):131.

34. Folayan MO, Alade M, Adeniyi A, El Tantawi M, Finlayson TL. Association between maternal socioeconomic factors, decision-making status, and dental utilization by children with early childhood caries in sub-urban Nigeria. J Public Health Dent. 2020;80(4):288-96.

35. Folayan MO, El Tantawi M, Oginni AB, Alade M, Adeniyi A, Finlayson TL. Malnutrition, enamel defects, and early childhood caries in preschool children in a sub-urban Nigeria population. PLoS ONE. 2020;15(7):e0232998.

36. Folayan MO, Oginni AB, El Tantawi M, Alade M, Adeniyi AA, Finlayson TL. Association between nutritional status and early childhood caries risk profile in a suburban Nigeria community. Int J Paediatr Dent. 2020;30(6):798-804.

37. Gibbs L, Waters E, de Silva A, Riggs E, Moore L, Armit C, et al. An exploratory trial implementing a community-based child oral health promotion intervention for Australian families from refugee and migrant backgrounds: a protocol paper for Teeth Tales. BMJ Open. 2014;4(3):e004260.

38. Folayan MO, Khami MR, Onyejaka N, Popoola BO, Adeyemo Yl. Preventive oral health practices of school pupils in Southern Nigeria. BMC Oral Health. 2014;14:83.

39. Nishi M, Bratthall D, Stjernswärd J. How to Calculate the Significant Caries Index (SiC Index). WHO Collaborating Centre Faculty of Odontology, University of Malmö, Sweden. 2001

40. Folayan MO, Khami MR, Folaranmi N, Popoola BO, Sofola OO, Ligali TO, Esan AO, Orenuga OO. Determinants of preventive oral health behaviour among senior dental students in Nigeria. BMC Oral Health. 2013;13:28.

41. Folayan MO, El Tantawi M, Chukwumah NM, Alade M, Oginni O, Mapayi B, Arowolo O, Sam-Agudu NA. Individual and familial factors associated with caries and gingivitis among adolescents resident in a semi-urban community in South-Western Nigeria. BMC Oral Health. 2021;21(1):166. 
42. Folayan MO, Sowole CA, Kola-Jebutu A, Owotade FJ. Risk factors for rampant caries in children from southwestern Nigeria. Afr J Med Med Sci. 2012;41(3):249-55.

43. Dentistry AAOP, Pediatrics AAO. Policy on early childhood caries (ECC): classifications, consequences, and preventive strategies. Pediatr Dent. 2011;30(7 Suppl):31-3.

44. Attin T, Hornecker E. Tooth brushing and oral health: how frequently and when should tooth brushing be performed? Oral Health Prev Dent. 2005:3(3):135-40.

45. Ojofeitimi EO, Esimai OA, Owolabi OO, Olaobaju OF, Olanuga TO. Breast feeding practices in urban and rural health centres: impact of baby friendly hospital initiative in Ile-Ife, Nigeria. Nutr Health. 2000;14(2):119-25.

46. Folayan MO, Sowole CA, Owotade FJ, Sote E. Impact of infant feeding practices on caries experience of preschool children. J Clin Pediatr Dent. 2010;34(4):297-301.

47. Folayan MO, Kolawole KA, Chukwumah NM, Oyedele T, Agbaje HO, Onyejaka N, Oziegbe EO, Oshomoji OV. Use of caries prevention tools and associated caries risk in a suburban population of children in Nigeria. Eur Arch Paediatr Dent. 2016:17(3):187-93.

48. dos Santos AP, Nadanovsky P, de Oliveira BH. A systematic review and meta-analysis of the effects of fluoride toothpastes on the prevention of dental caries in the primary dentition of preschool children. Commun Dent Oral Epidemiol. 2013;41(1):1-12.

49. El Tantawi M, Folayan MO, Mehaina M, Vukovic A, Castillo JL, Gaffar $\mathrm{BO}$, et al. Prevalence and data availability of early childhood caries in 193 United Nations Countries, 2007-2017. Am J Public Health. 2018;108(8):1066-72.

50. Xiao J, Alkhers N, Kopycka-Kedzierawski DT, Billings RJ, Wu TT, Castillo DA, et al. Prenatal oral health care and early childhood caries prevention: a systematic review and meta-analysis. Caries Res. 2019;53(4):411-21.
51. Nakai Y, Mori Y, Tamaoka I. Antenatal health care and postnatal dental check-ups prevent early childhood caries. Tohoku J Exp Med. 2016;240(4):303-8.

52. van Houte J, Gibbs G, Butera C. Oral flora of children with nursing bottle caries. J Dent Res. 1982;61(2):382-5.

53. Vania A, Parisella V, Capasso F, Di Tanna GL, Vestri A, Ferrari M, Polimeni A. Early childhood caries underweight or overweight, that is the question. Eur J Paediatr Dent. 2011;12(4):231-5.

54. Martins-Júnior PA, Vieira-Andrade RG, Corrêa-Faria P, Oliveira-Ferreira F, Marques LS, Ramos-Jorge ML. Impact of early childhood caries on the oral health-related quality of life of preschool children and their parents. Caries Res. 2013;47(3):211-8.

55. Folayan M, Olatubosun S. Early childhood caries-a diagnostic enigma. Eur J Paediatr Dent. 2018;19(2):88.

56. Xiao J, Alkhers N, Kopycka-Kedzierawski DT, et al. Prenatal oral health care and early childhood caries prevention: a systematic review and metaanalysis. Caries Res. 2019;53(4):411-21.

57. Newbrun E. Topical fluorides in caries prevention and management: a North American perspective. J Dent Educ. 2001;65(10):1078-83.

58. Lam PPY, Sardana D, Ekambaram M, Lee GHM, Yiu CKY. Effectiveness of pit and fissure sealants for preventing and arresting occlusal caries in primary molars: a systematic review and meta-analysis. J Evid Based Dent Pract. 2020;20(2):1014.

59. LeSaffre E, Mwalili SM, Declerck D. Analysis of caries experience taking inter-observer bias and variability into account. J Dent Res. 2004;83(12):951-5.

\section{Publisher's Note}

Springer Nature remains neutral with regard to jurisdictional claims in published maps and institutional affiliations.
Ready to submit your research? Choose BMC and benefit from:

- fast, convenient online submission

- thorough peer review by experienced researchers in your field

- rapid publication on acceptance

- support for research data, including large and complex data types

- gold Open Access which fosters wider collaboration and increased citations

- maximum visibility for your research: over $100 \mathrm{M}$ website views per year

At BMC, research is always in progress.

Learn more biomedcentral.com/submissions 